\title{
Corrigendum: Continental-scale temperature variability during the past two millennia
}

\section{PAGES $2 \mathrm{k}$ Consortium}

Nature Geoscience 6, 339-346 (2013); published online 21 April 2013; corrected after print 27 November 2015.

Since the original publication of this Progress Article, errors have been identified in the data set used for the Arctic temperature reconstruction. Accordingly, the following corrections have been made to the data set (see updated Supplementary Databases): (1) three records $s^{1-3}$ have been removed, as well as sections of five records ${ }^{4-8}$ that did not meet the authors' criteria for sensitivity to temperature; (2) the signs of the proxy temperature relation for two records $s^{9,10}$ have been corrected; and (3) a 50-year offset in the ages of one record ${ }^{11}$ has been corrected. Following these corrections, the period from 1941-1970 emerges as the second warmest 30-year period in the Arctic record, and 1971-2000 the third warmest, rather than the first and second warmest as reported in the original version. The ranked order of the best estimate of temperature indicates that the warmest 30-year period is centred on AD 395. No major conclusions have been affected by the corrections made to the Arctic data set including the conclusion that, during the period AD 1971-2000, the area-weighted average reconstructed temperature among regions was higher than any other time in nearly 1,400 years.

Table 1 has been revised to reflect the updated values of the number of lake sediments $(19$, not 22$)$ and the calibration $r$ value $(0.55$, not 0.56). Figures 2 and $4 \mathrm{~b}$ have been updated and replaced (also shown below) and the above corrections have been made in all online versions of the Progress Article. New versions of Supplementary Databases S1 and S2 have been uploaded online to reflect the updated version of the Arctic data set (v.1.1.1). A comparison of the original and revised Arctic data sets is available ${ }^{12}$. The Arctic data set, the reconstruction and its revision history are available at http://ncdc.noaa.gov/paleo/study/16973. The PAGES $2 \mathrm{k}$ data sets and any future updates are available from http://ncdc.noaa.gov/paleo/study/12621.

The authors thank D. Divine, S. McIntyre and K. Seftigen, who helped improve the Arctic temperature reconstruction by finding errors in the data set.

1. Gonyo, A. W., Yu, Z. \& Bebout, G. E. J. Paleolim. 48, 55-67 (2012).

2. Sha, L., Jiang, H. \& Knudsen, K. L. Holocene 22, 347-358 (2012).

3. Lapointe, F., Francus, P., Lamoureux, S. F., Saïd, M. \& Cuven, S. J. Paleolim. 48, 159-173 (2012).

4. Bird, B., Abbott, M., Finney, B. \& Kutchko, B. J. Paleolim. 41, 25-41 (2009).

5. D'Arrigo, R. et al. Global Planet. Change 65, 71-82 (2009).

6. Kirchhefer, A. Holocene 11, 41-52 (2001).

7. MacDonald, G. M., Case, R. A. \& Szeicz, J. M. Arctic Alpine Res. 30, 334 (1998).

8. Massa, C. et al. J. Paleolim. 48, 241-258 (2012).

9. Larsen, D. J., Miller, G. H., Geirsdóttir, Á. \& Thordarson, T. Quat. Sci. Rev. 30, 2715-2731 (2011).

10. Sejrup, H. P., Haflidason, H. \& Andrews, J. T. Quat. Sci. Rev. 30, 3181-3195 (2011).

11. Kaufman, D. S. et al. J. Paleolim. 48, 9-26 (2012).

12. McKay, N.P. \& Kaufman, D. Sci. Data 1, 140026 (2014).

Figure 2

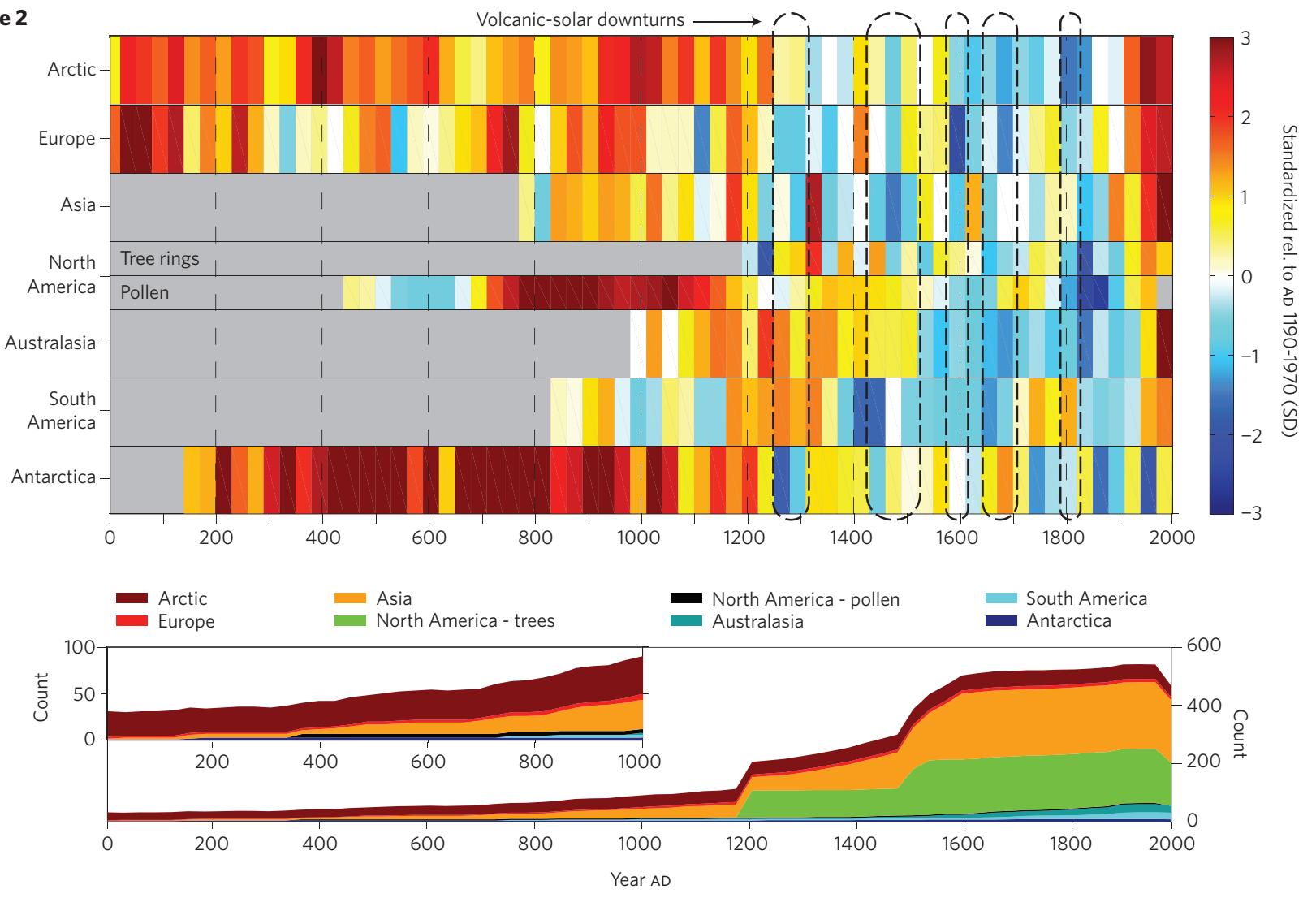


Figure 4b

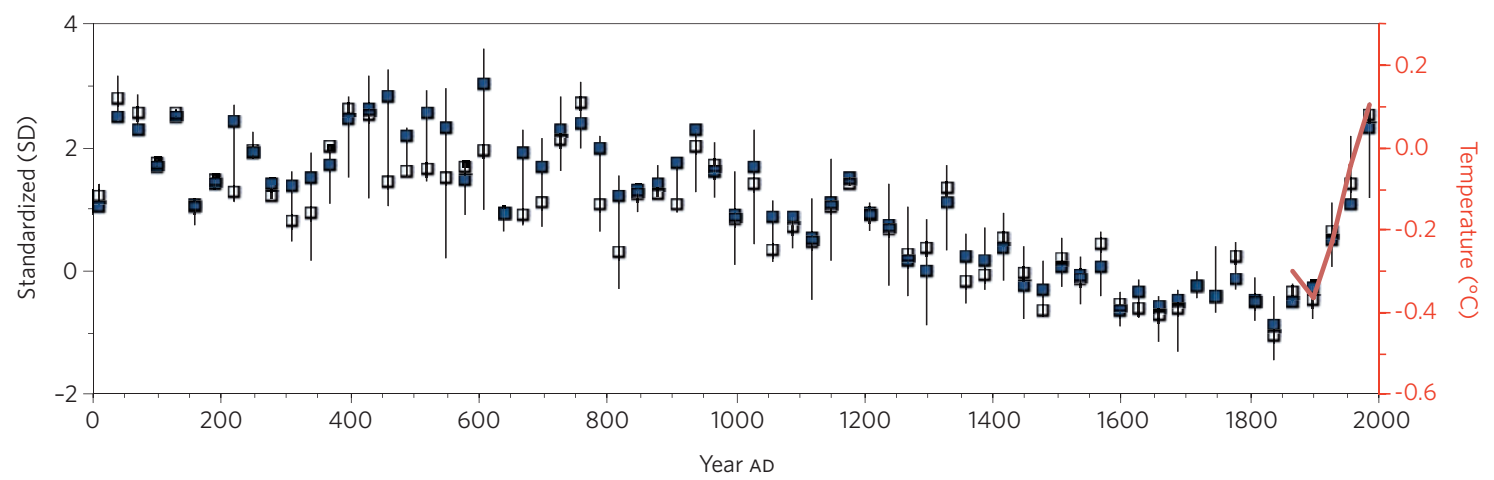

